\title{
Prevalence of risk factors of non-communicable diseases in a rural area of Bangladesh
}

\author{
Jasimuddin Ahmed ${ }^{1,2}$, M Mostafa Zaman ${ }^{1}$, Sohel R Choudhury² ,Tashfin Zissan¹, \\ Mehedi Hasan Ahmed ${ }^{1}$, Masud Ahmed ${ }^{1}$ \\ ${ }^{1}$ Ekhlaspur Center of Health (ECOH), Matlab North, Chandpur, ${ }^{2}$ National Heart Foundation Hospital \\ and Research Institute, Dhaka
}

\begin{abstract}
Keywords: NCDs risk factors, rural Bangladesh, population survey.
\end{abstract}

\begin{abstract}
:
Background: Data on risk factors of non-communicable diseases (NCDs) are still inadequate Bangladesh. More data, especially from rural population because 70 percent of Bangladeshi people leave in rural area, are necessary to plan intervention and monitor progress of NCD control. The aim of the study was to determine distribution and prevalence of risk factors of NCDs in a rural adult population of Bangladesh.

Method: A cross-sectional study targeting one adult (15 years or older) from each of 1088 households of a village was carried out in 2008. Among them 1011 participated. Information on age and education of the respondents and risk factors such as tobacco, fruit and vegetable intake, habit of added salt while taking the meal, blood pressure and waist circumference were obtained using standardized protocol.

Results: Mean age of the subjects was 42.4 years. Age adjusted prevalence of tobacco consumption was $59.5 \%$ (smoking $31.0 \%$ and smokeless tobacco use $36.3 \%$ ). More than nine in ten (92.8\%) of the respondents consumed less than 5 serving of fruit and/or vegetables per day. Nine in ten (88.5\%) used extra salt during meal. Prevalence of hypertension and central obesity was found $19.7 \%$ and $18.8 \%$ respectively.

Conclusion: NCD risk factors are widely prevalent even in this rural population having a traditional agricultural lifestyle. Interventions those are appropriate to this kind of community are needed to be developed in Bangladesh.
\end{abstract}

(Cardiovasc. j. 2017; 9(2): 122-128)

\section{Introduction}

Non-Communicable diseases (NCDs), principally cardiovascular diseases, cancer, chronic respiratory diseases and diabetes are the leading causes of death and disability globally. ${ }^{1}$ Most of these deaths are premature, i.e., deaths before the age of 70 years. Moreover, $80 \%$ of the deaths attributed to these diseases occur in the low and middle income countries. ${ }^{2}$ The burden of NCDs has already become a major health problem in Bangladesh. ${ }^{3}$ More than $60 \%$ deaths in Bangladesh are happening due to NCDs. ${ }^{4}$

NCDs are linked to a few major risk factors. Although a few population level studies on risk factors of NCDs have been published, ${ }^{5-7}$ we need more data points for setting the baseline and examining the trend as per global NCD monitoring framework. ${ }^{8,9}$ For control and prevention of NCDs in Bangladesh, we need to know the distribution of established risk factors of NCDs both in urban and rural areas. More emphasis on rural population is required because more than $70 \%$ of the people of Bangladesh live in rural area. This study aims at determining the prevalence of established common risk factors for NCDs among the adult population in a rural area of Bangladesh.

\section{Methods}

A survey was conducted among residents, aged 15 years or older, of Ekhlaspur village of Matlab North Sub-district, a rural area of Bangladesh during the period of November to December 2008. The area is located on the bank of river Meghna, about $60 \mathrm{~km}$ south-east of Dhaka city. It is an agricultural area and it takes about two to three hours by motor launch to reach nearby small towns. ${ }^{10}$

Ekhlaspur Centre of Health (ECOH), a local nongovernmental health promotion organization conducts periodic demographic surveys in the village and a complete list of households with demographic information of the residents was available. There were 1088 households in the village. ${ }^{11}$ Residents aged 15 years or above living in the village were the source population for this study. All households of the villages were visited by health assistants of ECOH for selection of one respondent from each household. To have similar representation of men and women, household were

Address of correspondence: Dr. Jasimuddin Ahmed, Department of Microbiology, National Heart Foundation Hospital and Research Institute, Dhaka, Bangladesh. E-mail: ahmedjasim1@gmail.com 
divided into male and female households. A list of male or female residents of a household was prepared during the visit by interviewers. Then Kish table was used to select one respondent from a household. A structured questionnaire was used to collect information about age, education, tobacco use, fruit and vegetable intake and habit of salt intake while taking meal. Sitting blood pressure and standing waist circumference were measured by standardized methods.

Information on tobacco use was collected for both smoking and smokeless forms. Those who smoked or used smokeless tobacco daily within the past 30 days were considered as "current" users. Respondents were asked for the number of days they ate fruit and vegetables in a typical week, and how many servings they ate on one of those days. Servings were measured by showing pictorial show-cards (for uncooked items) or measuring cups (cooked items).

Information on treatment of hypertension was sought by checking prescriptions or medicine strips if they claimed to be on treatment of the disease. Waist circumference was measured using a plastic measuring tape midway between the lower margin of the last palpable rib and the top of the hip bone to the nearest $0.5 \mathrm{~cm}$. Blood pressure was measured using ordinary aneroid sphygmomanometers (in $\mathrm{mm}$ of $\mathrm{Hg}$ ) on the left arm while the participants were in a sitting position after having a rest for at least 5 min. Korotkoff phase $\mathrm{V}$ was taken as diastolic blood pressure. A second reading was taken after 2 min and the mean of these measurements were used in the analysis.

This survey was done as a part of routine annual examination of villagers of Ekhlaspur done by
ECOH in participation of the community as a whole. Purpose of the health examination survey was explained to the community leaders and community consent was obtained. Subsequently participants' verbal consent was obtained but ethical clearance was not solicited because it was rather dictated by the community. All subjects detected to have risk factors were either counseled or brought under registry and treatment program of $\mathrm{ECOH}$ as per its mandate.

\section{Statistical analyses:}

Data were checked and entered in a database. Age and sex specific descriptive statistics of selected variables for all participants were calculated. Prevalence of NCD risk factors in each group was calculated. Hypertension was defined as systolic blood pressure $\geq 140 \mathrm{mmHg}$ or diastolic blood pressure $\geq 90 \mathrm{mmHg}$ or on anti-hypertensive medication. Central obesity was defined as waist circumference $\geq 91 \mathrm{~cm}$ in men and $\geq 81 \mathrm{~cm}$ in women. Low fruits and vegetable index was defined as less than 5 serving per day. Prevalence estimates were adjusted to WHO world population. ${ }^{12}$ All analyses were done using Statistical Package for the Social Sciences version 16.0.

\section{Results:}

In total, 1011 subjects participated in the study (response rate 93\%). Of the total respondents, $46.4 \%$ were male and mean age of the subjects was 42.4 (standard deviation 16.3) years. Among the respondents $15.4 \%$ were below 25 years and $10.7 \%$ were above 64 years. Median years of schooling were 2 years. One-third (32.5\%) of them had no formal education (Table I).

Table-I

Sociodemographic profile of the study participants.

\begin{tabular}{lccc}
\hline & $\begin{array}{c}\text { Men and Women } \mathrm{n}=1011 \\
\mathrm{n}(\%)\end{array}$ & $\begin{array}{c}\text { Men n=469 } \\
\mathrm{n}(\%)\end{array}$ & $\begin{array}{c}\text { Women } \mathrm{n}=542 \\
\mathrm{n}(\%)\end{array}$ \\
\hline Age groups, years & & & \\
$15-24$ & $156(15.4)$ & $86(18.3)$ & $70(12.9)$ \\
$25-34$ & $209(20.7)$ & $84(17.9)$ & $125(23.1)$ \\
$35-44$ & $231(22.8)$ & $110(23.5)$ & $121(22.3)$ \\
$45-54$ & $197(19.5)$ & $81(17.3)$ & $116(21.4)$ \\
$55-64$ & $110(10.9)$ & $51(10.9)$ & $59(10.9)$ \\
$65+$ & $108(10.7)$ & $57(12.2)$ & $51(9.4)$ \\
Educational achievement & & & \\
No formal education & $328(32.5)$ & $126(26.9)$ & $202(37.3)$ \\
Any primary (grades 1 to 5) & $422(41.7)$ & $194(41.4)$ & $228(42.1)$ \\
Any secondary (grades 6 to 10) & $233(23.0)$ & $129(27.5)$ & $104(19.2)$ \\
More than secondary (grades 11 or above) & $28(2.7)$ & $20(4.2)$ & $8(1.5)$ \\
\hline
\end{tabular}


Table-II

Distribution non-communicable disease risk factors in study population.

\begin{tabular}{|c|c|c|c|c|c|c|}
\hline Age groups & $\begin{array}{c}\text { Fruit, } \\
\text { servings/ } \\
\text { day }\end{array}$ & $\begin{array}{c}\text { Vegetables, } \\
\text { servings/ } \\
\text { day }\end{array}$ & $\begin{array}{c}\text { Vegetables/fruit, } \\
\text { servings/ } \\
\text { day }\end{array}$ & $\begin{array}{c}\text { Systolic } \\
\text { blood } \\
\text { pressure, } \\
\text { mmHg }\end{array}$ & $\begin{array}{l}\text { Diastolic } \\
\text { blood } \\
\text { pressure, } \\
\text { mmHg }\end{array}$ & $\begin{array}{c}\text { Waist } \\
\text { circumference, } \\
\mathrm{cm}\end{array}$ \\
\hline \multicolumn{7}{|c|}{ Men and women } \\
\hline $15-24$ & $0.4(0.3)$ & $1.8(0.6)$ & $2.2(0.7)$ & $113.9(10.3)$ & $72.5(9.1)$ & $71.1(8.4)$ \\
\hline $25-34$ & $0.4(0.3)$ & $1.9(0.5)$ & $2.1(0.7)$ & $113.9(11.1)$ & $72.4(9.5$ & $72.2(10.1)$ \\
\hline $35-44$ & $0.4(0.3)$ & $1.9(0.6)$ & $2.1(0.7)$ & $116.5(12.3)$ & $74.8(9.3)$ & $74.8(10.5)$ \\
\hline $45-54$ & $0.4(0.3)$ & $1.8(0.6)$ & $2(0.7)$ & $120.4(17.2)$ & $75.8(10.9)$ & $73.6(10.5)$ \\
\hline $55-64$ & $0.4(0.3)$ & $1.7(0.5)$ & $2.1(2.2)$ & $124.6(16.9)$ & $76.7(8.6)$ & $72.7(11.0)$ \\
\hline $65+$ & $0.4(0.2)$ & $1.8(0.6)$ & $2(0.7)$ & $133.2(22.2)$ & $81.3(10.9)$ & $72.6(9.1)$ \\
\hline Total & $0.4(0.3)$ & $1.8(0.6)$ & $2.1(1.0)$ & $118.9(15.8)$ & $75.0(10.1)$ & $73(10.1)$ \\
\hline \multicolumn{7}{|l|}{ Men } \\
\hline $15-24$ & $0.3(0.3)$ & $1.8(0.5)$ & $2.1(0.7)$ & $113.8(10.3)$ & $72.6(9.1)$ & $71.1(8.4)$ \\
\hline $25-34$ & $0.4(0.3)$ & $1.9(0.6)$ & $2.1(0.6)$ & $113.9(11.1)$ & $72.4(9.4)$ & $72.2(10.1)$ \\
\hline $35-44$ & $0.4(0.4)$ & $1.9(0.6)$ & $2.1(0.8)$ & $116.4(12.4)$ & $74.9(9.4)$ & $74.8(10.6)$ \\
\hline $45-54$ & $0.4(0.3)$ & $1.8(0.6)$ & $2.0(0.7)$ & $120.3(17.2)$ & $75.8(11.0)$ & $73.6(10.5)$ \\
\hline $55-64$ & $0.3(0.3)$ & $1.8(0.6)$ & $1.9(0.8)$ & $124.6(16.9)$ & $76.7(8.7)$ & $72.7(11.1)$ \\
\hline $65+$ & $0.4(0.2)$ & $1.9(0.7)$ & $2.1(0.7)$ & $133.1(22.1)$ & $81.2(10.9)$ & $72.6(9.1)$ \\
\hline Total & $0.4(0.3)$ & $1.8(0.6)$ & $2.1(0.7)$ & $118.9(15.9$ & $75.0(10.1)$ & $73.0(10.1)$ \\
\hline \multicolumn{7}{|l|}{ Women } \\
\hline $15-24$ & $0.3(0.4)$ & $1.9(0.7)$ & $2.2(0.8)$ & $112.5(12.3)$ & $71.5(11.1)$ & $70.1(8.6)$ \\
\hline $25-34$ & $0.2(0.3)$ & $1.9(0.5)$ & $2.1(0.7)$ & $112.3(12.1)$ & $70.3(9.9)$ & $71.5(10.5)$ \\
\hline $35-44$ & $0.2(0.3)$ & $1.9(0.6)$ & $2.1(0.7)$ & $115.3(11.4)$ & $714.6(9.6)$ & $73.5(11.1)$ \\
\hline $45-54$ & $0.2(0.3)$ & $1.8(0.6)$ & $2.1(0.7)$ & $122.8(18.3)$ & $76.6(11.4)$ & $71.2(12.0)$ \\
\hline $55-64$ & $0.2(0.3)$ & $1.7(0.5)$ & $2.3(3.0$ & $129.0(19.3)$ & $78.2(8.9)$ & $72.3(11.0)$ \\
\hline $65+$ & $0.2(0.2)$ & $1.70 .6)$ & $1.8(0.7)$ & $132.8(19.2)$ & $80.5(11.1)$ & $70.8(9.4)$ \\
\hline Total & $0.2(0.3)$ & $1.8(0.6)$ & $2.1(1.2)$ & $118.9(16.7$ & $74.6(10.8)$ & $71.7(10.7)$ \\
\hline
\end{tabular}

Results are mean (standard deviation)

Distribution (mean \& SD) of risk factors are presented in Table II and prevalence of risk factors in Table III. 


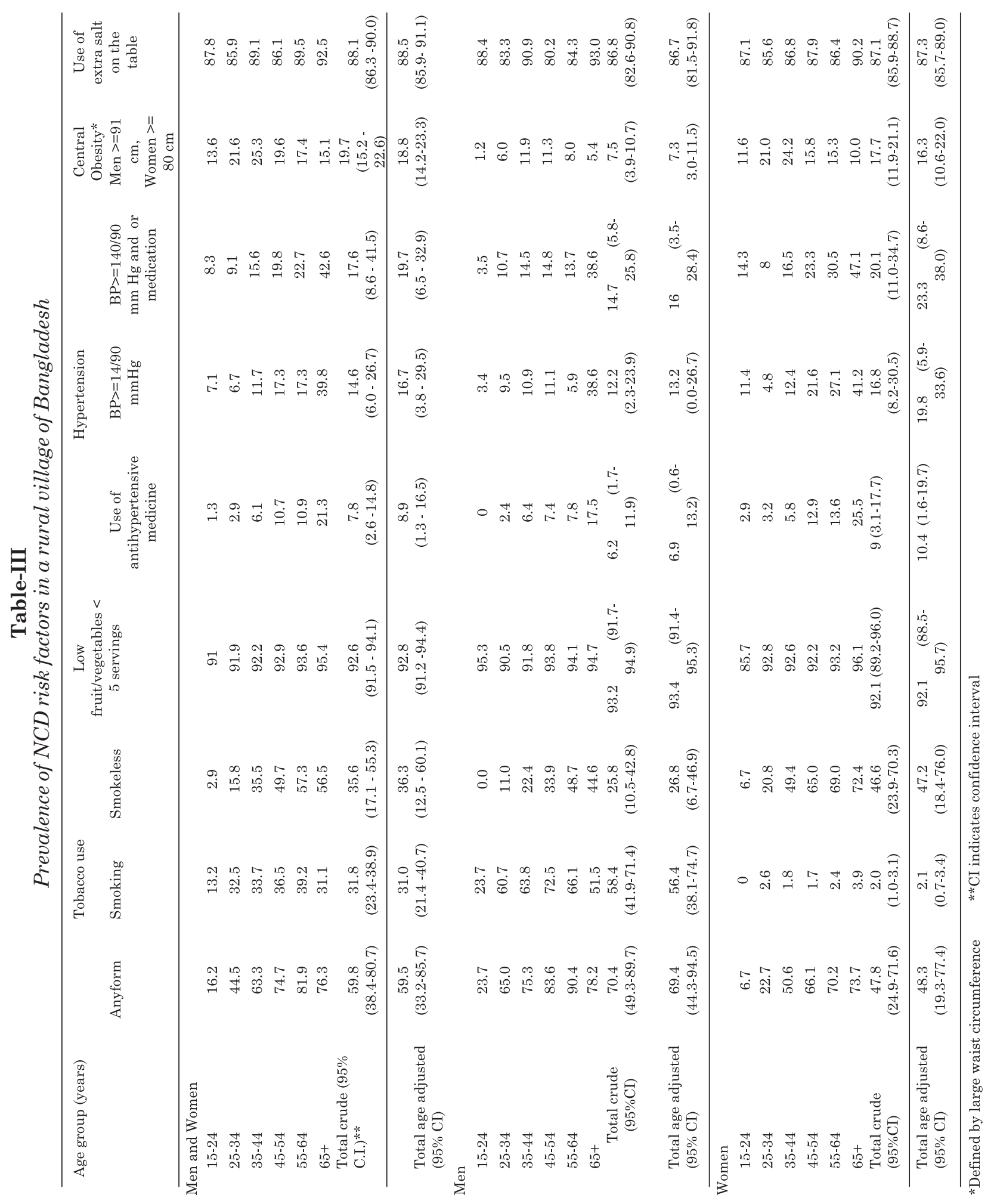


Fruit and vegetables: Mean (SD) per capita consumption of fruit and vegetables was 2.1 (1.0) servings per day. More than nine in 10 (92.8\%) respondents consumed less than recommended minimum 5 servings of fruit and/or vegetables per day.

Tobacco use: Smoking prevalence was very high in men whereas in women it is much lower than men in the area. Only fifteen women gave history of smoking. The overall prevalence of smoking was $31.0 \%$ (56.4\% men versus $2.1 \%$ women) and Prevalence of smokeless tobacco use was $36.3 \%$ (26.8\% in men and $47.2 \%$ in women).

Salt use: We found that more than 85 percent of the people use extra salt during meal. Prevalence of daily extra salt intake during meal was $86.7 \%$ in men and $87.3 \%$ in women.

Blood pressure status: Mean (SD) systolic pressure was 118.9 (15.8) $\mathrm{mmHg}$ and mean diastolic pressure was 75 (10.1). Prevalence of high blood pressure (systolic blood pressure e"140 mmHg or diastolic pressure e" $90 \mathrm{~mm} \mathrm{Hg}$ ) was 16.7\% (men; $13.2 \%$ ) and women $19.8 \%$ ). As per history, $8.9 \%$ respondents were taking medication for hypertension. Prevalence of hypertension defined by high blood pressure $(>=140 / 90 \mathrm{mmHg}$ ) or medication was 19.7 (men 16 and women 23.3)

Central obesity: Average waist circumference (as a measure of central obesity) was $73 \mathrm{~cm}$ and 71.7 $\mathrm{cm}$ in men and women respectively. Overall, $18.8 \%$ had central obesity. Women had a higher prevalence of central obesity ( $16.3 \%$ versus $7.3 \%$ ) than men.

\section{Discussion:}

In Bangladesh there are only a few studies have reported the prevalence of risk factors of NCDs. Our survey report showed a high prevalence of risk factors even in a rural area. This poses a significant threat for upcoming NCD epidemics. In specific terms high prevalence of tobacco use, hypertension, obesity, low consumption of fruit/ vegetable, and high consumption of salt while taking meal were observed.

Tobacco use is a major threat to health. The overall prevalence of smoking (31.0\%) observed in the present study is quite high than STEPS survey 2010 $(27 \%)^{7}$ and STEPS survey $2013(17 \%)^{8}$ done in Bangladesh. Smoking prevalence among men in the present study (58.4\%.) is comparable to that of Indonesia (54\%) ${ }^{13}$ and Vietnam (58\%) ${ }^{14}$ but was higher than India (42\%) ${ }^{15}$ and Maldives (40\%). ${ }^{16}$

In our study smoking prevalence among women was negligible (2.1\%), suggesting a better influence of social norms. On the other hand, high prevalence of smokeless tobacco consumption was observed by women. It is observed that proportion of tobaccouse increased consistently with age, the highest being in 50 years and above age-group in the areas. Bangladesh has a high cultural acceptability of smokeless tobacco. Tobacco Control Act 2005 did not have any mandate to control smokeless tobacco. This might have favored easy availability and use of smokeless tobacco products such as Zarda, Pan Masala, Gul, etc. ${ }^{17}$

We found low per capita consumption of fruit/ vegetable per day in our study which is similar that of STEPS surveys done in $2010^{7}$ and $2013 .^{8}$ Low consumption of fruits and vegetables probably could be due to the lack of awareness, especially in rural area. WHO attributes approximately three million deaths a year from NCDs to inadequate consumption of fruit and vegetables. ${ }^{18}$ Consumption of adequate fruits and vegetables not only prevents nutrient deficiency disorders but also reduces the risk of cardiovascular diseases. Goyal et $\mathrm{al}^{19}$ reported that increased consumption of fruits and vegetables is associated with a $16 \%$ lower risk of cardiovascular disease in Indian subcontinent. Availability of good-quality seeds, encouraging the farmers to grow vegetables and fruits, and public-awareness campaign about their benefits are some of the important strategies that may help increase the consumption of fruits and vegetables.

Obesity has been growing in Bangladesh. ${ }^{6}$ Although we have not measured height and weight; it can be easily guessed from our data that obesity has already become a problem even in this rural area. About one in five of our subjects have central obesity. The age adjusted prevalence is higher in women (16.3\%) compared to men $(7.3 \%)$. Their physical activity level might be lower than men. ${ }^{20}$ It is noteworthy that the central obesity is a peculiar characteristic of South Asian people that predispose them to metabolic syndrome and diabetes. ${ }^{21}$ Interventions those are appropriate for this population needs to be identified. 
High intake of sodium is one of the important contributing factors for high blood pressure. The present study found high age adjusted prevalence of hypertension in the area (19.7\%). This could be due to the excessive intake of salt during meal which is very common in our sample (88.5\%). It is also observed that high blood pressure is a major health problem in the elderly people. One striking feature of this sample is inadequate detection and treatment rate in spite of having a high prevalence of hypertension.

\section{Study Limitations:}

This is a single location study. Therefore the findings are not generalizable for Bangladeshi rural population at large. This study could not capture data on body mass index which is globally more commonly used as an index of obesity.

\section{Conclusion:}

Prevalence of NCD risk factors is high in this rural population. This high prevalence warrants intervention to reduce risk and to deal with the chronic diseases to which they contribute.

\section{Conflict of interest:}

We do not have any conflict of interest.

\section{Acknowledgements:}

We are indebted to the people of Ekhlaspur for participating in this survey and the community leaders to for making all necessary arrangements of the survey to establish a system of annual health checkup in this rural population. Staffs of $\mathrm{ECOH}$ (especially Mr. Nazrul Islam and Mr. Sadequl Islam) deserve special thanks for their hard work to complete the field work.

\section{Financial support:}

No external fund was used for this survey. Ekhlaspur Center of Health has done this survey with its own fund.

\section{References:}

1. Global status report on noncommunicable diseases 2014. World HealthOrganization, Geneva, Switzerland, 2014. Available at http://www.who.int/nmh/publications/ ncd-status-report-2014/en/[Last accessed on 11 May 2015].

2. Asaria P, Chisholm D, Mathers C, Ezzat Mi, Beaglehole R. Chronic disease prevention: health effects and financial costs of strategies to reduce salt intake and control tobacco use. Lancet 2007; 370:2044-53.

3. World Health Organization. Health Profile of Bangladesh. WHO Bangladesh 2003. Available at http:/ /www.whoban.org/country_ health_profile.html [Last accessed on 26 May 2013].

4. World Health Organization, Global Burden of Diseases. http://www.who.int/healthinfo/global_burden_disease/ estimates_country/en/index.htm (26 May 2016).

5. Zaman MM, Choudhury SR, Ahmed J, Talukder MH, Rahman AHMS. Blood glucose and Cholesterol levels in adult population of Bangladesh: Results from STEPS 2006 survey. Indian Heart Journal 2006; 68:52-56.

6. Zaman MM, Rahman MM, Rahman MR, Bhuiyan MR, Karim MN, Chowdhury MAJ. Prevalence of Risk Factors for Non-Communicable Diseases in Bangladesh: Results from STEPS Survey 2010. Indian Journal of Public Health 2016; 60: 17- 25.

7. Zaman MM, Bhuiyan MR, Karim MN, Zaman M, Rahman MM, Akanda AW, et al. Clustering of NonCommunicable Diseases risk factors in Bangladeshi adult: An analysis of STEPS survey 2013. BMC Public Health 2015; 15: 659.

8. World Health Organization. Global Strategy on Diet, Physical Activity and Health, Assembly 57 (WHA resolution 57.17) in May 2004. Geneva, World Health Organization.

9. World Health Organization. Framework Convention on Tobacco Control, World Health Assembly 56 (WHA resolution 56.1) 2003.Agenda item 13, 21 May 2003, Geneva, World Health Organization

10. Zaman MM, Choudhury SR, Ahmed J, Yoshiike N, Numan SM, Islam MS, et al. Plasma Lipids in a rural Population of Bangladesh. Eur.J.Cardiovasc Prev Rehabil 2006; 13:444 - 448 .

11. Zaman MM, Choudhury SR, Ahmed J, Hussain SMA, Sobhan SMM. Prevalence of stroke in a rural population of Bangladesh. Global Heart 2015; 10: 333-335.

12. Ahmad OB, Boschi-Pinto C, Lopez AD, Murray CJL, Lozano R, Inoue M. Age standardization of rates: a new WHO standard, GPE Discussion Paper Series:No.31. Geneva, Switzerland: World Health Organization; 2001.

13. Ng N, Stenlund H, Bonita R, Hakimi M, Wall S, WeinehallL. Preventable risk factors for noncommunicable diseasesin rural Indonesia: prevalence study using WHO STEPS approach. Bull World Health Organ 2006; 84: 305-313.

14. Hoang VM, Byass P, Dao LH, Nguyen TK, Wall S. Risk factorsfor chronic disease among rural Vietnamese adults and the association of these factors with sociodemographic variables: findings from the WHO STEPS survey in rural Vietnam, 2005.Prev Chronic Dis 2007; 4.

15. Sugathan TN, Soman CR, Sankaranarayanan K. Behavioural risk factors for non-17 communicable 
diseases among adults in Kerala, India. Indian $J$ Med Res 2008; 127: 555-563.

16. Aboobakur M, Latheef A, Mohamed AJ, Moosa S, Pandey RM, Krishnan A, et al. Surveillance for noncommunicable disease risk factors in Maldives: results from the first STEPS survey in Male. Int J Public Health 2010; 55:489-496.

17. Gupta V, Yadav K, Anand K. Patterns of tobacco use across rural, urban, and urban-slum populations in a north Indian community. Indian $J$ Community Med 2010; 35: 245-251.

18. Bhagyalaxmi A, Atul T, Shikha J. Prevalence of Risk Factors of Non-communicable Diseases in a
District of Gujarat, India. J Health Popul Nutr 2013 Mar; 31(1): 78-85.

19. Goyal A, Yusuf S. The burden of cardiovascular disease in the Indian subcontinent. Indian J Med Res 2006; 124:235-44.

20. Moniruzzaman M, Zaman MM, Islalm MS ,H.A.M.N. Ahasan HAMN, Kabir H, Yasmin R. Physical activity levels in Bangladeshi adults: results from STEPS survey 2010.Public Health, 2016; April 7.pilli 500333506(16)00085-8

21. Yajnik CS, Yudkin JS. The Y-Y paradox. Lancet 2004; 363:163. 